\title{
"I Feel Almost as Though I've Lived This Before": Insights from Sexual and Gender Minority Men on Coping with COVID-19
}

\author{
Katherine G. Quinn ${ }^{1}$ (D) Jennifer L. Walsh ${ }^{1}$. Steven A. John ${ }^{1}$ - Alan G. Nyitray ${ }^{1,2}$
}

Published online: 12 September 2020

๑) Springer Science+Business Media, LLC, part of Springer Nature 2020

\begin{abstract}
As communities struggle with how to cope with the health and social consequences of coronavirus disease 2019 (COVID19), sexual and gender minority men living with or affected by the HIV/AIDS epidemic have important insights into how to cope with uncertainty, public health protocols, and grief. We recruited sexual and gender minority men using online networking apps from April 18-24, 2020 to enroll a longitudinal cohort. We analyzed baseline qualitative data from openended responses using content analysis to examine how the HIV/AIDS epidemic has helped sexual minority men with the current COVID-19 pandemic. Of the 437 participants who completed the survey, 155 (35\%) indicated that HIV/AIDS had helped them cope with COVID-19. Free-response data from those 135 of those participants clustered around four themes: (1) experience having lived through a pandemic, (2) experience coping with stigma, (3) familiarity with public health protocols, and (4) belief in collective action. Based on the experiences of these men, public health approaches centered on resilience and collective action could be particularly helpful in responding and coping with COVID-19—especially if the pandemic persists over longer periods of time.
\end{abstract}

Keywords COVID-19 $\cdot$ Coping $\cdot$ Stigma $\cdot$ Collective action $\cdot$ HIV epidemic $\cdot$ Lessons learned

\section{Introduction}

Coronavirus disease 2019 (COVID-19) is arguably the worst public health crisis in the United States (US) since the 1918 flu pandemic. Yet, for many, COVID-19 is reminiscent of the 1980s HIV/AIDS epidemic, which was similarly characterized by uncertainty, lack of testing and treatments, new public health protocols, and severe illness and death of thousands of citizens. COVID-19 and HIV have also both disproportionately impacted Black individuals. Estimates suggest that 1 in 2 Black men who have sex with men (MSM) will acquire HIV in their lifetime, compared to 1 in 11 white MSM [1]. HIV diagnosis rates are between 22 and 33 times higher among Black individuals as compared to white [2].

Katherine G. Quinn

kaquinn@mcw.edu

1 Department of Psychiatry and Behavioral Medicine, Center for AIDS Intervention Research (CAIR), Medical College of Wisconsin, 2071 N. Summit Ave., Milwaukee, WI 53208, USA

2 Clinical Cancer Center, Medical College of Wisconsin, Milwaukee, WI, USA
Similar disparities exist in COVID-19 infections and deaths [3]. Residents in US counties that are majority-Black have COVID-19 infection rates three times that of majority-white counties and a death rate almost six times that of white counties [4]. The disparities in HIV and COVID-19 are attributable to socio-structural and political conditions that shape an individual's risk for disease including, racism, stigma, limited access to healthcare, and socioeconomic challenges. While vastly different diseases, e.g., with regard to transmission mode and natural history, the lessons learned and experiences of individuals who are living with or at risk from HIV may be useful in understanding and addressing the psychosocial and public health challenges associated with COVID-19 [5].

In addition to informing the public health response to COVID-19, there is much to be learned from individuals who have experience with HIV/AIDS. Individuals who lived through the HIV epidemic of the 1980s, particularly sexual minority men and men living with HIV, have unique experiences that may offer insight into the experience of living through a pandemic like COVID-19. Colloquially referred to as the "gay plague" [6], between 1981 and 2000 nearly 450,000 people in the United States died from complications 
from HIV and AIDS, the majority of whom were men, infected via male-to-male sexual contact [7]. Many sexual minority men diagnosed with HIV in the " $80 \mathrm{~s}$ and early ' 90 s survived, although they may continue to face difficult physical, social, and mental health challenges [8]. The HIV epidemic continues to disproportionately affect sexual and gender minority men, with nearly 25,000 new HIV infections attributable to male-to-male sexual contact each year [9]. While the current HIV epidemic is smaller in scope and urgency than in its earlier years, sexual and gender minorities continue to face the threat of HIV and the public health challenges that accompany epidemics.

As communities struggle with how to cope with the health and social consequences of COVID-19, we may find that sexual and gender minority men living with or affected by the HIV epidemic have important insights into how to cope with uncertainty, public health protocols, and grief. In this study we examine qualitative data from open-ended survey responses to understand how the HIV/AIDS epidemic has helped sexual minority men cope with the current COVID-19 pandemic.

\section{Methods}

Data are from the baseline COVID-19, HIV, and Sexuality (CHAS) study, a longitudinal study which aims to characterize the impact of COVID-19 on sexual and gender minority individuals. Individuals were eligible to participate if they were aged 25 or older and resided in one of the study target cities: Chicago, Milwaukee, Detroit, Minneapolis, and Houston. Study cities align with this study's parent grant that is examining sexual health of sexual and gender minority men in these cities. Data were collected April 18-24, 2020, which was approximately four weeks following the initiation of stay-at-home orders in these cities (March 21, 25, 24, 27, and 24, respectively). Recruitment was conducted online using advertisements on social media platforms. Interested participants completed a brief eligibility survey. Eligible participants read an informational letter and agreed to participate prior to the baseline survey. We received a waiver of written consent. Participants received a $\$ 20$ reloadable debit card for completing the online survey, which was sent to participants via mail. To reduce fraudulent responses, we limited advertising eligibility criteria to ensure potential participants did not know how to become eligible for the study. Additionally, we screened for potential duplicate responses by examining contact information (name, phone number, email, and mailing address) via REDCap [10]. All procedures were approved by the Institutional Review Board at the Medical College of Wisconsin.

Participants were asked whether experience with HIV/ AIDS had helped them cope with the COVID-19 pandemic.
Of the 437 participants who completed the baseline survey and were enrolled into the longitudinal study, 155 (28\%) agreed the HIV epidemic helped them cope with COVID19. Individuals who reported that their experiences with HIV helped them cope with the COVID-19 pandemic were significantly older $(\mathrm{p}<0.001)$, more likely to be living with HIV ( $p<0.001)$ and more likely to be married or cohabitating $(p<0.01)$ than those with other responses. There were no significant differences by race, ethnicity, gender identity, sexual orientation, or city. Participants who agreed that the HIV epidemic helped them to cope with the COVID-19 pandemic were asked an open-ended follow-up question: How has your experience with AIDS and HIV helped you cope with COVID?" (answered by 135 participants (87\%)). There were no significant demographic differences between those who did and did not respond to the open-ended item. We created a codebook to organize the qualitative data into categories and applied codes using MAXQDA qualitative analysis software. First, all responses were coded with age, race/ethnicity, HIV status, and study city. This allowed for analysis to examine whether there were any differences in experiences and perspectives based on these key demographic features. We then read open-ended responses to inductively develop a list of codes [11] using conceptual content analysis [12] to broadly categorize responses. Coded data were then analyzed in-depth to answer the research question: How have individuals' experiences with AIDS and HIV helped them cope with COVID? Data were analyzed to explore the salience of codes and identify primary themes [12].

\section{Results}

Baseline data were collected from 437 participants, aged 25-76 years, from April 18-24, 2020. Data presented here are from the subsample of participants $(N=135)$ who indicated that their experience with the HIV/AIDS epidemic helped them cope with COVID-19. The average age of participants was $44.81(\mathrm{SD}=11.74)$ with ages ranging from 26 to 76 years old. Most participants identified as men (96\%), gay $(87 \%)$, and white $(69 \%)$. A total of $19 \%$ identified as Black and $17 \%$ were Latinx. Nearly a third $(27 \%)$ were married or cohabitating. Nearly half (44\%) of participants reported living with HIV. Demographic characteristics are presented in Table 1.

We analyzed open-ended responses about how participants' experiences with HIV have helped them to cope with COVID-19 and identified several themes: (1) experience having lived through a pandemic, (2) experience coping with stigma, (3) notions of personal responsibility, and (4) belief in collective action. Data presented below are verbatim written responses to the open-ended question and are included to 
Table 1 Participant characteristics

\begin{tabular}{|c|c|c|c|c|c|c|}
\hline & $\begin{array}{l}\text { Overall } \\
(N=135)\end{array}$ & $\begin{array}{l}\text { Chicago } \\
(n=71)\end{array}$ & $\begin{array}{l}\text { Milwaukee } \\
(n=20)\end{array}$ & $\begin{array}{l}\text { Detroit } \\
n=10)\end{array}$ & $\begin{array}{l}\text { Minneapolis } \\
(n=14)\end{array}$ & $\begin{array}{l}\text { Houston } \\
(n=20)\end{array}$ \\
\hline $\begin{array}{l}\text { Age } \\
M(S D) \text { [range] }\end{array}$ & $\begin{array}{c}44.81(11.74) \\
{[26-76]}\end{array}$ & $\begin{array}{c}44.10(11.85) \\
{[26-68]}\end{array}$ & $50.40(11.82)[30-70]$ & $\begin{array}{c}47.60(11.12) \\
{[32-64]}\end{array}$ & $41.14(7.80)[29-55]$ & $\begin{array}{l}42.90 \\
\quad(12.71) \\
{[28-76]}\end{array}$ \\
\hline \multicolumn{7}{|l|}{ Race } \\
\hline White & $69 \%$ & $65 \%$ & $85 \%$ & $90 \%$ & $79 \%$ & $50 \%$ \\
\hline Black & $19 \%$ & $21 \%$ & $5 \%$ & $10 \%$ & $14 \%$ & $35 \%$ \\
\hline Another race & $12 \%$ & $14 \%$ & $10 \%$ & $0 \%$ & $7 \%$ & $15 \%$ \\
\hline Latinx ethnicity & $17 \%$ & $16 \%$ & $15 \%$ & $0 \%$ & $14 \%$ & $10 \%$ \\
\hline \multicolumn{7}{|l|}{ Gender identity } \\
\hline Man & $96 \%$ & $94 \%$ & $100 \%$ & $90 \%$ & $100 \%$ & $100 \%$ \\
\hline Trans man & $2 \%$ & $3 \%$ & $0 \%$ & $0 \%$ & $0 \%$ & $0 \%$ \\
\hline Non-binary & $2 \%$ & $1 \%$ & $0 \%$ & $10 \%$ & $0 \%$ & $0 \%$ \\
\hline Another identity & $1 \%$ & $1 \%$ & $0 \%$ & $0 \%$ & $0 \%$ & $0 \%$ \\
\hline \multicolumn{7}{|l|}{ Sexual orientation } \\
\hline Gay & $87 \%$ & $89 \%$ & $95 \%$ & $60 \%$ & $86 \%$ & $85 \%$ \\
\hline Bisexual & $6 \%$ & $6 \%$ & $5 \%$ & $20 \%$ & $0 \%$ & $5 \%$ \\
\hline Queer & $6 \%$ & $4 \%$ & $0 \%$ & $20 \%$ & $14 \%$ & $5 \%$ \\
\hline I don't know or other & $1 \%$ & $1 \%$ & $0 \%$ & $0 \%$ & $0 \%$ & $5 \%$ \\
\hline \multicolumn{7}{|l|}{ Relationship status } \\
\hline Married & $16 \%$ & $13 \%$ & $35 \%$ & $10 \%$ & $7 \%$ & $15 \%$ \\
\hline Cohabitating & $11 \%$ & $13 \%$ & $5 \%$ & $20 \%$ & $0 \%$ & $15 \%$ \\
\hline Divorced/separated & $6 \%$ & $4 \%$ & $5 \%$ & $10 \%$ & $7 \%$ & $10 \%$ \\
\hline Single (no steady partner) & $54 \%$ & $55 \%$ & $50 \%$ & $50 \%$ & $71 \%$ & $45 \%$ \\
\hline Single (steady) & $13 \%$ & $16 \%$ & $5 \%$ & $10 \%$ & $14 \%$ & $15 \%$ \\
\hline Living with HIV & $44 \%$ & $39 \%$ & $55 \%$ & $50 \%$ & $43 \%$ & $45 \%$ \\
\hline
\end{tabular}

Notes Totals may not sum to $100 \%$ due to rounding

demonstrate these four themes. Additional qualitative data are presented in Table 2 .

\section{Experience Having Lived Through a Pandemic}

Although we did not collect information on the length of time living with HIV, not all participants living with HIV were diagnosed in the 1980s and ' $90 \mathrm{~s}$. Those who disclosed living with HIV for several decades drew parallels between their experiences living through the uncertainty and panic of the early HIV epidemic and the current COVID-19 pandemic. As one participant noted:

I have lived as an HIV-positive person for 18 years and I remember the hardships and the frightening news coverage that HIV had in the beginning. -65-year-old white, gay man, living with HIV.

Other participants described similar experiences:

I am HIV-positive from a time when it was considered lethal, but now it's just chronic (due to medications). So, I am not too concerned about having to face the possibility of another illness that could be lethal. -48-year-old white, gay man, living with HIV.
Participants who were diagnosed with HIV when it was "considered lethal" were familiar with the uncertainty of emerging viruses without effective treatment or vaccinations. This was also evident among individuals who were HIV-negative, but had nevertheless lived through the trauma of the early HIV epidemic. For some, having lived through and survived the 1980s HIV epidemic provided resilience in the face of uncertainty. Yet, it also brought back memories of loss and adversity. Several participants described having lost close friends and partners due to HIV. As one individual stated:

I grew up in the ' $80 \mathrm{~s}$ and ' $90 \mathrm{~s}$ and had friends and lovers die. I'm familiar with this type of thing, but not comfortable $100 \%$. -50-year-old white, gay man, HIV-negative.

Thus, while the current pandemic felt familiar, participants were also acutely aware of the potential life-changing nature of public health crises.

\section{Experience Coping with Stigma}

Participants also drew parallels and made distinctions between HIV-related stigma and COVID-19 stigma. 
Table 2 Representative quotes

\begin{tabular}{|c|c|c|}
\hline Theme & Representative quote & Participant characteristics \\
\hline \multirow[t]{6}{*}{$\begin{array}{l}\text { Experience having lived } \\
\text { through a pandemic }\end{array}$} & $\begin{array}{l}\text { Having been through it, it has allowed me to have } \\
\text { some perspective. As in, we can all get through this. } \\
\text { Must take it day by day }\end{array}$ & 42-year old white gay cis-man living with HIV \\
\hline & $\begin{array}{l}\text { I always tell myself if I'm able to live with HIV, } \\
\text { then the thought of the current COVID-19 climate } \\
\text { doesn't really harm me mentally }\end{array}$ & $\begin{array}{l}\text { 35-year-old African American gay cis man living with } \\
\text { HIV }\end{array}$ \\
\hline & $\begin{array}{l}\text { I have lived with HIV since the 1980s. I am glad that } \\
\text { people are aware. I lived in Jersey City during the } \\
\text { height of the AIDS pandemic. I visited Hart Island. } \\
\text { Seeing people buried there awakened my memories }\end{array}$ & 57-yearold white gay cis-man living with HIV \\
\hline & $\begin{array}{l}\text { It has given me hope that something so destructive } \\
\text { will become less impactful given time }\end{array}$ & 51-year-old white gay cis-man, HIV-negative \\
\hline & I feel almost as though I've lived this before & 59-year-old white gay cis-man, HIV-negative \\
\hline & $\begin{array}{l}\text { I know how traumatic this is, so I sort of know what } \\
\text { to expect. I've learned how to deal with epidemics }\end{array}$ & 56-year-old white gay cis-man, HIV-negative \\
\hline \multirow[t]{2}{*}{ Experience coping with stigma } & $\begin{array}{l}\text { Having lived with HIV for } 25 \text { years has given me } \\
\text { ways to cope. There is still a negative stigma with } \\
\text { HIV, so dealing with COVID is a bit easier }\end{array}$ & 57-year-old white gay cis-man living with HIV \\
\hline & $\begin{array}{l}\text { It has made me think about the idea of contagious- } \\
\text { ness and the larger setting and the euphemism of the } \\
\text { word 'sick' to refer to people with a specific disease. } \\
\text { Also the recognition of safe vs. safer practices }\end{array}$ & 45-year-old white gay cis-man, HIV-negative \\
\hline \multirow[t]{4}{*}{ Personal responsibility } & $\begin{array}{l}\text { I know that there will always be some medicine made } \\
\text { eventually and to hold out hope. And to use protec- } \\
\text { tion, always }\end{array}$ & $\begin{array}{l}\text { 30-year-old African American gay cis-man living with } \\
\text { HIV }\end{array}$ \\
\hline & $\begin{array}{l}\text { Realized I have to take precautions, but can't let it } \\
\text { control my life }\end{array}$ & 44-year-old white gay cis-man, HIV-negative \\
\hline & $\begin{array}{l}\text { I understand the importance of taking preventative } \\
\text { measures to not pass things }\end{array}$ & $\begin{array}{l}\text { 26-year-old Latino gender non-binary individual, HIV- } \\
\text { negative }\end{array}$ \\
\hline & $\begin{array}{l}\text { A willingness to follow recommended guidelines from } \\
\text { health officials for staying healthy }\end{array}$ & 54-year-old white gay cis-man, HIV-negative \\
\hline \multirow[t]{4}{*}{ Belief in collective action } & $\begin{array}{l}\text { Empathy is greater, civic responsibility more recog- } \\
\text { nizable }\end{array}$ & $\begin{array}{l}\text { 39-year-old African American gay cis-man living with } \\
\text { HIV }\end{array}$ \\
\hline & $\begin{array}{l}\text { Just remembering the strength of our community in } \\
\text { overcoming hardship and stigma }\end{array}$ & 49-year-old white gay man, HIV-negative \\
\hline & $\begin{array}{l}\text { Just knowing that people did make it through, and } \\
\text { really unionized and made it a political issue too }\end{array}$ & $\begin{array}{l}\text { 28-year-old multiracial Latino gay cis-man, HIV- } \\
\text { negative }\end{array}$ \\
\hline & $\begin{array}{l}\text { Understanding knowledge is power, and once we } \\
\text { understand how something is spread, we can better } \\
\text { plan for how to contain it, then hopefully cure it }\end{array}$ & 39-year-old white, gay trans man, HIV-negative \\
\hline
\end{tabular}

Participants described the deep social stigma surrounding HIV and gay men and several noted that COVID-19 does not carry the same stigma. As one participant explained:

There is no social stigma with COVID-19, so having felt stigmatized as an HIV-positive man, COVID-19 is somehow easier to deal with. -57-year-old white gay man, living with HIV.

Other participants, however, did notice some stigma associated with COVID-19 and described how their experience with HIV stigma made them more mindful of the powerful effects and consequences of stigma. One individual stated:

It has helped to be cautious about imposing stigma on those who have contracted COVID-19. It has also helped me to realize that epidemics change things dramatically, but that life ultimately goes on (if we are lucky enough not to die). - 42-year-old white gay man living with HIV.

Similarly, another participant living with HIV noted:

I understand the value in not alienating a percentage of the population who may be positive with an illness, while still being mindful of proper best practices in terms of not allowing transmission of things to occur. This, while understanding that if someone has an illness, it is just that they have an illness. It does not become the identity of that person. - 39-year-old white gay man living with HIV.

As these individuals explained, their experiences with HIV stigma have made them cautious about stigmatizing 
persons who contract COVID-19 and allowed them to recognize the virus as an illness, rather than a person's identity.

\section{Personal Responsibility}

The public health protocols set in place following the outbreak of COVID-19-social distancing, wearing face masks - were, in some ways, familiar to men who have been attuned to public health messages around sexual health and the need for personal and social responsibility. Participants likened wearing masks to wearing condoms, noting that it was necessary to protect themselves and others. As one participant, a 30-year-old Black man living with HIV, noted: "I am used to protecting myself." Participants also described a personal responsibility in the name of public health.

I have an understanding that we are personally responsible to conduct ourselves in the interest of public health concerns. -62-year-old white gay man, HIVnegative.

Similarly, another participant stated:

You have to do what is safe for you and the public. It's not the time to be selfish. If you do what is told and expected of you, you will be ok. -43-year-old Latino gay man, HIV-negative.

As these participants noted, individual-level COVID-19 protections are in place not only to protect an individual, but also to protect the public. The notions of selflessness and personal responsibility were highlighted as necessary for prevention of both COVID-19 and HIV. Participants also described familiarity in not knowing whether they were infected with an asymptomatic virus; a shared characteristic of HIV and COVID-19.

I have familiarity with the uncomfortable feeling of knowing there's a chance you have a disease and could pass it on to someone else. Since I have felt that before, perhaps I am better at coping with it. - 35-year-old white gay man, HIV-negative.

As this participant, an HIV-negative man, described, there is anxiety associated with knowing a virus could be asymptomatic and spread to others. As he noted, his familiarity with this uncertainty improved his coping with a similar uncertainty of COVID-19.

\section{Belief in Collective Action}

Finally, participants expressed a strong belief in collective action in response to public health crises. Several individuals recalled how the gay community came together in the $1980 \mathrm{~s}$ to push the government toward action. Importantly, several younger gay men who did not live through the height of the
HIV epidemic reflected on the early years of the HIV epidemic and the ways in which the gay community responded to "government inaction" and a public health crisis. As one individual stated:

[My experience with the HIV epidemic] has given me greater perspective and hope. An example of heroism and bravery to look back on. -27-year-old white gay man, HIV-negative.

Although this participant did not experience the 1980s HIV epidemic and was not living with HIV, he noted the heroism and bravery of that time. For many, the community leaders that emerged during the early HIV epidemic and worked to fight HIV stigma and demand government support and biomedical research, provided a sense of hope and evidence that collective action and community organizing can be effective strategies. As another individual stated:

Working in HIV research and studying the AIDS epidemic has given me hope that collective action on the local level helps people's wellness and survival in the face of an epidemic. -27-year-old white gay man, HIVnegative.

In addition to local collective action, participants also cited a lack of inaction at a federal level, drawing comparisons between the federal responses to COVID-19 and HIV.

I learned how to channel anger at poor leadership into action. This time it is virtual rather than going to dieins or demonstrations. Educating others, writing to legislators, city and state officials, and probably wasting my time writing to Trump to ask him to stop lying. -66-year-old white gay man, HIV-negative.

While current public demonstrations may look different due to social distancing required of COVID-19, this participant's experience with collective action during the HIV epidemic helped him learn to channel his anger at leadership in productive ways. Other participants similarly drew parallels between current "government inaction" and President Trump's perceived lack of leadership in the response to COVID-19 and President Reagan's limited response to HIV.

\section{Discussion}

As the COVID-19 pandemic continues to unfold and the health and psychosocial consequences emerge, it will be important to examine how the COVID-19 pandemic affects sexual and gender minorities and people living with HIV. Additional research is needed to understand the impact of COVID-19 on people living with HIV. For example, there is some evidence that suggests the social distancing required to prevent COVID-19 may negatively influence the sexual [13] 
and mental health [14] of LGBTQ individuals and disrupt HIV care [15]. The long-term impacts of social distancing measures will need to be examined to help social and health organizations, particularly those serving people living with HIV, respond appropriately to patient needs. However, these qualitative data from sexual minority men early in the pandemic (April 2020) shed light on some of the psychosocial and public health challenges and opportunities associated with COVID-19. This study provides early data on the ways in which individuals who have experience with the HIV/ AIDS epidemic are using those experiences to cope with the COVID-19 pandemic. Study participants, including those living with and without HIV, described experience and confidence in following public health protocols, fighting stigma, and coping with public health crises.

Study participants drew parallels between the HIV epidemic and COVID-19 pandemic, which was particularly evident in participants' experience living through a public health crisis and complying with public health recommendations. Among older participants who had lived through the HIV epidemic of the 1980s, participants expressed familiarity and perspective. Individuals noted they had "lived this before" and recognized both the traumatic aspects of a pandemic and the ability to "get through this." Similarly, participants noted a familiarity with following public health recommendations (e.g. condom use) for both their own and the public's health and protection. This was evident among those living with and without HIV. Future research is needed to examine how this sense of personal responsibility and experience with a pandemic influences their engagement with COVID-19 protection efforts (e.g. mask wearing, social distancing).

There is mounting evidence of COVID-19 stigma [16, 17] that for some individuals in this study, was reminiscent of HIV stigma. Stigma is a social process that reflects societal norms and values and is frequently rooted in exclusion and othering of racial, sexual, gender, and other minorities $[18,19]$. In public health crises, stigma may be framed as blame, responsibility, and risk, as has been seen in both HIV and COVID-19 [20, 21]. Groups who are disproportionately affected by infectious diseases may be blamed for outbreaks, be accused of not following public health protocols, and can internalize such stigma, contributing to harmful psychological effects. These experiences, coupled with the effects of existing racial stigmas or inequities, can contribute to reduced access to and acceptability of healthcare, limited uptake of testing and treatment adherence, and disparities in health outcomes [22]. The early stigma surrounding HIV was rooted in the perceptions of who was at risk for HIV, particularly gay men, and its sexual transmission [23]. While some study participants did not perceive COVID-19 stigma to be as pervasive and detrimental as HIV stigma, others noted that their experience with HIV made them cautious about stigmatizing individuals with COVID.

Stigma is often closely tied to personal responsibility [19, 24], which was another theme in our findings. Participants in this study described their experience with implementing public health measures (i.e. condom use) to protect themselves and their sexual partners from HIV. When the spread of a disease is perceived to be based on controllable individual factors (e.g. condom use, mask wearing) rather than external factors (e.g. structural racism or inequities), empathy is significantly reduced, and affected individuals face greater blame for the spread of disease [24, 25]. Limiting the spread of COVID-19 has required individual behaviors such as face masks, social distancing, and other sanitation methods that keep both individuals and others around them healthy. While instrumental in reducing the spread of COVID-19, such approaches can be used to shame, stigmatize, and blame individuals who do not follow public health protocols. Similarly, it can lead to blame among those who do contract COVID-19, as they may be viewed as irresponsible or to blame for their illness. Early in the pandemic, Asian communities were blamed for the spread of COVID19 [26]. This blame has continued as President Trump and other politicians referred to COVID-19 as the "Kung Flu" or "Chinese virus," perpetuating anti-Chinese stigma and xenophobia [27-29]. Similarly, as COVID-19 began to disproportionately impact Black and Latinx individuals in the US, blame and stigma followed [30].

Resilience was also central to the themes identified in our study, and our findings suggest that collective action could be a mechanism to help bring people together during a challenging socio-political time during COVID-19. Collective action, reminiscent of 1980s AIDS activism, could be a useful tool in advocating for federal funding and strong public health policies to combat COVID-19, encourage prevention, and hold political leaders accountable for action and inaction during this public health emergency. For some, President Trump's handling of the COVID-19 crisis brought to mind how President Reagan ignored early warnings about HIV and refused to publicly acknowledge the HIV crisis [31]. In the wake of government inaction, organizers and community leaders, including the activist group ACT UP, played a critical role in spreading information about HIV prevention and experimental treatment options. They staged demonstrations on Wall Street [32] and the FDA [33], and, as one participant recalled, staged "die-ins," which ultimately forced the FDA to permit access to experimental drug treatments for people living with HIV and AIDS [34]. Not only did participants who lived during these times describe the importance of these actions, but one younger individual described such actions as "an example of heroism and bravery to look back on." 
There were few notable differences in experiences or perspectives by participant age. However, older individuals, particularly those living with HIV, are at higher risk for COVID-19 related complications and mortality [35], and thus, may have different perspectives or anxieties about the pandemic. Similarly, older participants were alive during the height of the HIV crisis in the 1980s, giving them a different experience than younger individuals who are living with the current HIV epidemic. Effective antiretroviral therapy has significantly prolonged the lifespan of individuals living with HIV [36, 37] and the availability of pre-exposure prophylaxis provides an effective biomedical HIV prevention tool $[38,39]$. Similarly, we did not identify any differences by race or ethnicity. However, given the trajectory of COVID-19 since April and its devastating impact on Black communities, in-depth qualitative data may be useful in understanding the experiences of Black people living with and at risk for HIV during the pandemic. Despite parallels, COVID-19 and HIV are distinct illnesses with vastly different trajectories and experiences for people who become infected. Since its identification, HIV has been associated with marginalized populations - gay men, intravenous drug users, people in poverty, people of color [23], and people living with and at risk for HIV have faced myriad consequences of HIV-, race-, and sexuality-related stigmas [23]. As study participants noted, people living with HIV have continued to face a level of stigmatization not seen among individuals who have been diagnosed with and cured of COVID-19. Fear and misinformation, which have been key characteristics of the early COVID-19 pandemic, can contribute to stigma [22], and as the pandemic unfolds, stigma may emerge as a consequence of our public response to COVID-19 [17].

Our research is not without limitation. This research was conducted online, advertised on social media, geolocated to five cities in the U.S. Heartland, and conducted during one week at the height of the pandemic, which may not be representative of other times. However, this research was conducted within the constraints of human subjects research during the COVID-19 pandemic, and based on qualitative analysis, our themes did not seem to be influenced by local differences. Rather our data appear to be a reflection of the national response to COVID-19. It is possible that perceptions could change over time, particularly as states and local municipalities enact unique strategies to responding to COVID-19. Second, we collected qualitative data via free-response items in an online survey, which could have resulted in less depth to our data as we were unable to probe for additional details. Nonetheless, analysis of free-response data is a valid method of qualitative inquiry [40], which allowed rapid collection of timely data during a public health emergency. Finally, study participants are predominantly white $(69 \%)$. There are significant racial disparities in COVID-19 and Black and Latinx individuals are disproportionately affected [3]. We did analyze data to examine any thematic differences in responses between white and Black and Latinx participants but did not identify any patterns. However, these free response data, in contrast to in-depth interviews, prohibit deeper analysis. Additional research that examines these differences and the ways in which COVID-19 has affected Black and Latinx LGBTQ individuals is warranted, as is research that provides greater insight into any potential differences in experience based on length of time living with HIV, experiences with HIV stigma, and other similar individual and social factors.

\section{Conclusion}

This study is ongoing, and we continue to collect longitudinal data about sexual and gender minorities' experiences with COVID-19, sheltering in place, sexual behaviors, and mental health. We anticipate this data will provide a more comprehensive understanding of the effects of COVID-19 and provide data to inform public health policy, practice, and research.

In summary, we collected free-response data from 136 sexual and gender minority men located in five cities in the U.S. Heartland about how their experiences with HIV/ AIDS had helped them cope with COVID-19. Participants described their experiences living through a different pandemic, coping with stigma, familiarity with public health protocols, and belief in collective action. Based on the experiences of these men, public health approaches centered on resilience and collective action could be particularly helpful in responding and coping with COVID-19-especially if the pandemic persists over longer periods of time.

Acknowledgements We are grateful for the contributions of study participants. Special thanks to the CHAS research team who assisted with study implementation. Author support was provided from the National Institute of Mental Health (K01-MH112412, PI: Quinn; K01-MH118939, PI: John). The content is solely the responsibility of the authors and does not necessarily represent the official views of the National Institutes of Health.

\section{References}

1. Hess K, Hu X, Lansky A, Mermin J, Hall HI. Lifetime risk of a diagnosis of HIV infection in the United States. Ann Epidemiol. 2017;27:238-43.

2. Crepaz N, Hess KL, Purcell DW, Hall HI. Estimating national rates of HIV infection among MSM, persons who inject drugs, and heterosexuals in the United States. AIDS. 2019;33:701-8.

3. Garg S, Kim L, Whitaker M, O'Halloran A, Cummings C, Holstein R, et al. Hospitalization rates and characteristics of patients hospitalized with laboratory-confirmed Coronavirus Disease 2019-COVID-NET, 14 States, March 1-30, 2020. MMWR Morb Mortal Wkly Rep. 2020;69:458-64. 
4. Thebault $\mathrm{R}, \mathrm{Ba}$ Tran $\mathrm{A}$, Williams $\mathrm{V}$. The conronavirus is infecting and killing black Americans at an alarmingly high rate. Washington Post. 2020 Apr 7; Available from: https://www.washington post.com/nation/2020/04/07/coronavirus-is-infecting-killing-black -americans-an-alarmingly-high-rate-post-analysis-shows/?arc40 $4=$ true

5. Edelman EJ, Aoun-Barakat L, Villanueva M, Friedland G. Confronting another pandemic: lessons from HIV can inform our COVID-19 response. AIDS Behav. 2020;12:1-3.

6. Curran JW, Jaffe HW, Centers for Disease Control. AIDS: the early years and CDC's response. MMWR Surveill Summ Morb Mortal Wkly report Surveill Summ. 2011AIDS;60:64-9.

7. Centers for Disease Control and and Prevention. HIV and AIDSUnited States, 1981-2000. MMWR Morb Mortal Wkly Rep. 2001;50:430-4.

8. Quinn KG, Murphy MK, Nigogosyan Z, Petroll AE. Stigma, isolation and depression among older adults living with HIV in rural areas. Ageing Soc. 2020;40:1352-70.

9. Centers for Disease Control and Prevention. HIV Surveillance Report, 2018 (Updated). HIV Surveill. Report, 2018. 2019. Available from: https://www.cdc.gov/hiv/library/reports/hiv-surveillan ce.html

10. Teitcher JEF, Bockting WO, Bauermeister JA, Hoefer CJ, Miner $\mathrm{MH}$, Klitzman RL. Detecting, preventing, and responding to "fraudsters" in internet research: ethics and tradeoffs. J Law Med Ethics. 2015;43(1):116-33.

11. Saldana J. The coding manual for qualitative researchers. 3rd ed. Thousand Oaks, CA: SAGE; 2016.

12. Hsieh HF, Shannon SE. Three approaches to qualitative content analysis. Qual Health Res. 2005;15:1277-88.

13. Alpalhão $M$, Filipe $P$. The Impacts of isolation measures against SARS-CoV-2 infection on sexual health. AIDS Behav. 2020;24(8):2258-9.

14. Marziali ME, Card KG, McLinden T, Wang L, Trigg J, Hogg RS. Physical distancing in COVID-19 may exacerbate experiences of social isolation among people living with HIV. AIDS Behav. 2020. https://doi.org/10.1007/s10461-020-02872-8.

15. Brennan DJ, Card KG, Collict D, Jollimore J, Lachowsky NJ. How might social distancing impact gay, bisexual, queer, trans and two-spirit men in Canada? AIDS Behav. 2020. https://doi. org/10.1007/s10461-020-02891-5.

16. Brooks SK, Webster RK, Smith LE, Woodland L, Wessely S, Greenberg N, et al. The psychological impact of quarantine and how to reduce it: rapid review of the evidence. Lancet. 2020;395:912-20.

17. Logie CH, Turan JM. How do we balance tensions between COVID-19 public health responses and stigma mitigation? Learning from HIV research. AIDS Behav. 2020. https://doi. org/10.1037/lat0000129.

18. Link BG, Phelan JC, Hatzenbuehler ML. Stigma and social inequality. In: McLeod J, Lawler E, Schwalbe M, editors. Handb soc psychol inequal. Dordecht: Springer; 2014. p. 49-64.

19. Goffman E. Stigma: notes on the management of spoiled identity. Garden City, NY: Anchor Books; 1963.

20. Page KR, Venkataramani M, Beyrer C, Polk S. Undocumented US Immigrants and COVID-19. N Engl J Med. 2020. https://doi. org/10.1056/NEJMp2005953.

21. Wirawan DN. Stigma and discrimination: Barrier for ending AIDS by 2030 and achieving the $90-90-90$ targets by 2020 . Public Heal Prev Med Arch. 2019

22. Stangl AL, Earnshaw VA, Logie CH, Van Brakel W, Simbayi LC, Barré I, et al. The health stigma and discrimination framework: a global, crosscutting framework to inform research, intervention development, and policy on health-related stigmas. BMC Med. 2019;17:31.

23. Valdiserri RO. HIV/AIDS stigma: an impediment to public health. Am J Public Health. 2002;92:341.
24. Courtenay-Quirk C, Wolitski RJ, Parsons JT, Gomez CA. Is HIV/AIDS stigma dividing the gay community? Perceptions of HIV-positive men who have sex with men. AIDS Educ Prev. 2006;18:56-67.

25. Ramirez-Valles J, Molina Y, Dirkes J. Stigma towards PLWHA: The role of internalized homosexual stigma in Latino gay/ bisexual male and transgender communities. AIDS Educ Prev. 2013;25:178-81.

26. Haynes $\mathrm{S}$. As coronavirus spreads, so does xenophobia and antiAsian racism. Time. 2020

27. Rogers K, Jakes L, Swanson A. Trump Defends Using 'Chinese Virus' Label, Ignoring Growing Criticism. New York Times. New York; Available from: https://www.nytimes.com/2020/03/18/us/ politics/china-virus.html

28. Blake A. Trump defends "China Virus" as term for COVID-19: "We have great Asian support, and they understand." Washingt Times. Available from: https://www.washingtontimes.com/ news/2020/aug/6/trump-defends-china-virus-as-term-for-covid -19-we- $/$

29. Papenfuss M. Trump Uses Racist Terms 'Kung Flu' And 'Chinese Virus' To Describe COVID-19. Huffingt Post. Available from: https://www.huffpost.com/entry/trump-kellyanne-conway-coron avirus_n_5eeebc5dc5b6aac5f3a46b45

30. Kendi I. Stop blaming Black people for dying fo the coronavirus. Atl. Available from: https://www.theatlantic.com/ideas/archi ve/2020/04/race-and-blame/609946/

31. Paules CI, Eisinger RW, Marston HD, Fauci AS. What recent history has taught us about responding to emerging infectious disease threats. Ann Intern Med. 2017;167:805-11.

32. Flyer of the first ACT UP action, March 24, 1987, Wall Street, New York City. ACT UP AIDS Coalit. to Unleash Power. Available from: https://actupny.org/documents/1stFlyer.html

33. Aizenman N. How to demand a medical breakthough: Lessons from the AIDS fight. Natl Public Radio. 2019 Feb 9; Available from: https://www.npr.org/sections/health-shots /2019/02/09/689924838/how-to-demand-a-medical-breakthrou gh-lessons-from-the-aids-fight

34. Crimp D. Before Occupy: How AIDS Activists Seized Control of the FDA in 1988. Atl. 2011; Available from: https://www.theat lantic.com/health/archive/2011/12/before-occupy-how-aids-activ ists-seized-control-of-the-fda-in-1988/249302/

35. Shahid Z, Kalayanamitra R, McClafferty B, Kepko D, Ramgobin D, Patel R, et al. COVID-19 and older adults: what we know. J. Am. Geriatr. Soc. 2020;68:926-9.

36. Hogg RS. Understanding the HIV care continuum. Lancet HIV. 2018;5:e269-e270270.

37. Kay ES, Batey DS, Mugavero MJ. The HIV treatment cascade and care continuum: updates, goals, and recommendations for the future. AIDS Res Ther. 2016;13:1-7.

38. Anderson PL, Glidden DV, Liu A, Buchbinder S, Lama JR, Guanira JV, et al. Emtricitabine-tenofovir concentrations and preexposure prophylaxis efficacy in men who have sex with men. Sci Transl Med. 2012;4:151-25.

39. Donnell D, Baeten JM, Bumpus NN, Brantley J, Bangsberg DR, Haberer JE, et al. HIV protective efficacy and correlates of tenofovir blood concentrations in a clinical trial of PrEP for HIV prevention. J Acquir Immune Defic Syndr. 2014;66:340-8.

40. O'Cathain A, Thomas KJ. "Any other comments?" Open questions on questionnaires - A bane or a bonus to research? BMC Med Res Methodol. 2004;4:25.

Publisher's Note Springer Nature remains neutral with regard to jurisdictional claims in published maps and institutional affiliations. 